\title{
Evaluating the Impact of Wind Speed Modification onthe Performance of Vertical Axis Wind Turbines
}

\author{
Kenneth W Corscadden ${ }^{1}, \mathrm{~N}$ Greeno ${ }^{2}$ \\ ${ }^{I}$ Department of Engineering, Faculty of Agriculture, Dalhousie University, PO Box 550, Truro, Nova Scotia, \\ Canada, B2N $5 E 3$ \\ ${ }^{2}$ Mechanical Engineering Graduate, Dalhousie University, Halifax, Nova Scotia
}

\begin{abstract}
The integration of vertical axis wind turbines (VAWT) into building designs is an emerging yet growing market that has the potential to establish energy generating facilities inherent within the building structure. Although a VAWT can accept wind from any direction, the placement of turbines in relation to prevailing wind directions when combined with the structural architecture of the building and physical plant equipment such as heating, ventilation and air conditioning units (HVAC) can have a significant impact on turbine generating performance. This project investigates the potential performance improvement that might be obtained by optimal turbine placement for particular structural shapes and demonstrates the need for high resolution wind analysis software to validate placement options. Simulations and scale model field tests are used to identify the potential improvements.
\end{abstract}

Keywords: Vertical Axis Wind Turbines, Optimal Turbine Placement, High Resolution Wind Analysis, Integrated Wind Energy Production

\section{INTRODUCTION}

An increased awareness of the negative environmental effects of fossil fuels and the need for energy security has resulted in a changing energy infrastructure on a global scale ${ }^{1}$, with wind energy recognized as a major contributor to renewable energy technology ${ }^{2}$. The wind energy market has been dominated by Horizontal Axis Wind Turbines (HAWT), the performance of which, are affected by hub height, installed locations and wind patterns. The efficiency of these turbines increases with turbine size creating demand for larger generators, blade span and installation heights. Thor and WeisTaylor $^{3}$ state that past research and development has encouraged rapid development of the large scale wind energy industry, exceeding growth in both the computer and cellular phone industries. The International Energy Agency ${ }^{4}$ has identified continual development and application of innovative wind generation technology as crucial components of future growth in the wind energy industry. This drive in scale however does little to improve performance of smaller scale wind turbines, a growing market further fuelled by Renewable Energy Obligations or Feed In Tariffs (FIT)'s that target individual or residential scale installations as evidenced in many countries around the world ${ }^{5,6,7}$. The reduced efficiencies of smaller scale HAWT's however mean that installation heights and clear wind paths both upstream and downstream of the turbine have an even greater impact on turbine performance and hence payback. Ironically the investment required for small turbines means that taller poles and longer cable runs, which allow turbine positioning further from buildings to gain better wind regimes, become a large portion of the project costs.

A Vertical Axis Wind Turbine (VAWT) is a small or medium scale turbine designed for installation in disturbed wind patterns inherent around and on top of buildings, referred to as the "built environment". A VAWT offers several advantages when compared to small scale HAWT's; they are omni-directional, suitable for building integration such as rooftop installations, and perform well in distributed wind patterns. Early attempts at vertical axis turbines, arguably did not achieve competitive performance results. Recent advances in technology, design and applications however have seemingly allowed a resurgence of these turbines, but with a small installation base, independent performance data is less readily available $8,9,10,11$. The inherent ability of vertical axis turbines to perform in distributed wind patterns creates the potential of improving overall turbine output by modifying the wind regime, a view supported by Bertenyiet al ${ }^{12}$ who indicate that VAWT's when designed properly can actually perform better in disturbed wind patterns.

One topic of current research in urban environments is the capture and use of wind patterns around buildings as a mechanism for increasing wind speed, referred to as ducted wind. The issue of ducted wind is an emerging research topic and has been addressed by a number of authors. Beller ${ }^{13}$ has presented an overview of the application of urban wind in Europe and attempts to identify applicable technology and suitable locations in high-rise office buildings based on roof top wind regimes. In another study Beller ${ }^{14}$ proposes the use of Computational Fluid Dynamics (CFD) as a tool to analyze the potential performance of horizontal axis turbines placed on the roof top of Castle House, a high rise office building in London, England. This approach however is based on the use of existing horizontal turbines and uses a sloping roofline to optimize wind flow. Robert et $\mathrm{al}^{15}$ have investigated duct and spoiler design options to utilize wind flow prior to reaching the rooftop and diverting this through a ducting system. Their results claim an increase of up to $30 \%$ in wind speed. Grant and Kelly ${ }^{16}$ have developed a ducted wind turbine simulation model that suggests significant increased power outputs can be achievable with ducted wind turbine designs. Several authors ${ }^{17,18,19,20}$ have considered the suitability of small turbines for roof top mounting, but this work does not consider their suitability when integrated into the building structure nor the potential of developing an alternative structure designed specifically for an individual location.

This paper presents the results of a research project conducted at Dalhousie University Agricultural Campus, to investigate the potential performance improvement that might be possible with strategic placement of VAWT in the built environment. This research does not investigate the potential of a ducted wind turbine, one that is integrated into a duct within a building, but rather considers the impact of performance of a VAWT, combined with wind speed modification using existing building infrastructure such as HVAC equipment. This work has two main objectives, the first is to determine via 
simulation, the optimal shape that can be used to modify the wind regime when applied to aVAWT and the second is to verify the simulated results by constructing a one third scale model for field testing to allowcomparison of the simulation results with actual field performance data.

\section{EXPERIMENTAL DESIGN}

This research began with a theoretical analysis of the potential impact that structural shapes can have on wind regimes. Two software programs were used to test and evaluate hypothetical designs. The first, Google Sketch Up, was used to create a series of three dimensional (3D) models encompassing different sizes and structural geometry. These models were then integrated into Virtual wind, an analysis program, which was used computational fluid dynamics (CFD) to simulate wind testing on the range of 3D models. The results of these tests were used to identify the optimal structural design on a quantitative basis. To validate these findings, a scale model was produced to allow physical in field testing and acquisition of primary test data.

Initial tests of structural shapes, identified a cube as the optimal structure to provide uniform enhanced wind speed, Figure 1(a). This design was adopted for this experiment for a number of reasons. Firstly, it exhibits uniform configuration, and resulted in the greatest increase in flow velocity within the structure. Secondly, the cube resembles structures one might find in the urban or rural environment and should be easy and relatively inexpensive to build. The performance of the cube was evaluated based on the wind speed increase expected at the centre or the interior of the cube as a function of free stream wind speed. A VAWT would be located at the centre of the cube, therefore interior dimensions will be dictated by turbine size and the exterior dimensions based on the desired increase in wind speed, referred to as a multiplying factor.

The interior cube dimensions are defined by "h"and "w" and the exterior dimensions defined by $\mathrm{H}$ and $\mathrm{W}$ shown in Figure 1(b). Assuming that a reduction in pressure, which will be caused by an increase in wind velocity will not impact turbine performance (based on drag), then a theoretical increase in speed can be determined due to the reduction in area caused by the change in wind flow from a free stream flow to a constricted flow through the cube. Using $A_{1}$ and $V_{1}$ as the external surface area and wind velocity with $A_{2}$ and $V_{2}$ as the interior parameters then the following ideal theoretical relationship can be made for a constant wind densityp, eqn (1), where subscripts "e" and "i" represent exterior and interior features of the cube.

$\mathrm{A}_{\mathrm{e}} * \mathrm{~V}_{\mathrm{e}}=\mathrm{A}_{\mathrm{i}} * \mathrm{~V}_{\mathrm{i}}$

The potential increase in wind speed is therefore determined by the ratio of $A_{e}$ to $A_{i}$, referred to as the cube ratio.

\section{SIMULATIONS}

A cube model was created using "Google Sketchup". The model included interior and exterior dimensions and prevailing wind angle as variables to investigate the potential impact of wind direction on the interior wind speed and to facilitate testing of different cube ratios and.

Two main simulations were conducted.

The first evaluates the impact that prevailing wind direction has on the interior wind speed for a fixed cube ratio. Due to the symmetric shape of the cube only the angles $0^{\circ}$ to $45^{\circ}$ needed to be tested. Angles of $1^{\circ 1}, 9^{\circ}, 18^{\circ}, 27^{\circ}, 36^{\circ}$, and $45^{\circ}$ were used to create a range of data, Figure 2.

In the second simulation, a constantwind speed of $3.5 \mathrm{~m} / \mathrm{s}$ and prevailing wind angle of $36^{\circ}$ are used for 36 cube ratios ranging from 2 to 15 . If the theoretical assumption shown in eqn (1) is correct, one would expect an increase in wind speed which corresponds to the cube ratio. The authors acknowledge that the potential increase identified in eqn (1) relates only to wind speed and not to power output from a turbine.

\subsection{Simulation Results}

The results for the first simulation provide a measure of the expected increased wind speed detected at the centre of the cube for a constantfree stream wind speed of $3.5 \mathrm{~m} / \mathrm{s}$ and prevailing wind anglesranging from 0 to 45 degrees. Figure 3 displays the results, which show that wind approaching the cube at an angle of $36^{\circ}$ produces a corresponding maximum interior wind speed.In the best case scenario the simulation resulted in a speed increase from $3.5 \mathrm{~m} / \mathrm{s}$ to $5.77 \mathrm{~m} / \mathrm{s}$ which equates to a wind speed multiplier of 1.648 , a $64.8 \%$ increase.

The results of the second simulation are shown in Figure 4, which were obtained for a fixed prevailing wind angle of $36^{\circ}$ and a constant free stream wind speed of $3.5 \mathrm{~m} / \mathrm{s}$. Figure 4 displays the cube ratios plotted against the wind speed multipliers, which range from 1.2 to 2.2. Although the results show an increase in wind speed multiplier for increased cube ratio, there is an order of magnitude difference. The results plotted in Figure 4 however show a correlation coefficient of 0.9272 indicating significant correlation between cube ratio and wind speed multiplier. Rearrangement of the line equation, Figure 4 provides an indication of the expected wind speed multiplier one might expect for a particular cube ratio.

$x=\frac{y+12.698}{12.901}$

Where $\mathrm{x}=$ wind speed multiplier and $\mathrm{y}=$ cube ratio.

\section{SCALE MODEL TESTING}

In order to investigate this further, a scale model was constructed. The model was built using $60 \mathrm{c}$ by $120 \mathrm{~cm}$ thick kiln dried wood to produce the frame and $6 \mathrm{~mm}$ agricultural polyethylene material for the side walls of the cube. The model cube had exterior dimensions of $3 \mathrm{~m}$ by $3 \mathrm{~m}$ with internal dimension of $1 \mathrm{~m}$ by $1 \mathrm{~m}$ resulting in a cube ratio of 9 . These dimensions represent a 1/3 scale model based on a V3.5 VAWT produced by Cleanfield Energy Inc, Ontario. Using eqn (2)

${ }^{1}$ Virtual wind did not permit simulations using a wind direction of $0^{\circ}$ so $1^{\circ}$ was used instead. 
with a cube ratio of 9 , one should expect an internal wind speed multiplier of 1.68 if the optimum wind direction of $36^{\circ}$ can be maintained.

The cube was placed on a trailer at approximately $80 \mathrm{~cm}$ from the ground in a field of relatively short grass. Although the cube is located close to the ground, the objective of the field experiment is to compare the difference in wind speed and not the absolute wind speed. It is acknowledged that placing the cube at a higher elevation would result in higher recorded free stream wind speeds and perhaps allow for a greater wind speed differential between the wind speed measured inside and outside the cube.

The field experiment uses two cup anemometer sensors, one located inside the cube and a cup anemometer and direction sensor locatedon $3 \mathrm{~m}$ tripod outside the cube,Figure 5. The interior and exterior anemometer sensors were identified as model numbers S-WSA-M003 and S-WCA-M003 respectively, obtained from Hoskins Scientific. A HOBO U30 weather proof data logger was used with a 6 watt solar panel. Bothanemometerswere positioned at the same elevation.

\subsection{Field Test Resultsand Discussion}

The data represented in this paper was obtained over one month, at a sampling rate of once per minute. The data was analyzed in accordance with British Wind Energy Association wind turbine performance standard guidelines ${ }^{21}$. The wind data was placed in a database using bins ranging from $3 \mathrm{~m} / \mathrm{s}$ to $13 \mathrm{~m} / \mathrm{s}$. Wind speeds of less than the cut-in speed for the V3.5 VAWT of $3 \mathrm{~m} / \mathrm{s}$ were removed. The average wind speed recorded above the cut-in speed by the external and internal wind sensors was $4.9 \mathrm{~m} / \mathrm{s}$ and $5.12 \mathrm{~m} / \mathrm{s}$ respectively. Thisinterior/exterior speed differential results in a wind speed multiplier of only 1.046over the entire test period. This is significantly less than the wind speed multiplier produced from the simulation. To investigate this further, the prevailing wind directions were identified and wind speeds analyzed. The initial simulations for the cube structure, Figure 3 indicate that a reduction in wind speed will be experienced if the cube is not positioned with the predominant wind direction at $36^{\circ}$. In this case, the dominant wind directions were found to be between 18 and 22.5 degrees, as shown in Figure 6. Figure 9 shows an overlay of the cube on the wind rose which identifies the less than optimal dominant wind direction. By using the multiplier identified for wind angles, it is estimated that a $16 \%$ reduction in wind speed would be experienced if the cube is not positioned at $36^{\circ}$. Even with a $16 \%$ increase in wind speed the interior wind speed measured in the field experiment would only increase from $5.12 \mathrm{~m} / \mathrm{s}$ to $5.94 \mathrm{~m} / \mathrm{s}$, resulting in a wind speed multiplier of 1.21, a multiplier that the simulation results in Figure 4 predict from a cube ratio of two.

To investigate this further, the wind speed distribution was examined. Figure 7 displays the recorded wind speed distributions both inside and outside the cube. It shows that both wind speed measurements exhibit a Rayleigh distribution as one would expect, however a shift in the distribution occurs for the interior wind speeds. This discovery has the potential to greatly impact power production.

The wind speed data produced from the simulations was incorporated into a power calculation to provide an indication of the potential improvement in energy production that might be expected for a particular VAWT. The equation used to model the available power that can be harnessed from the wind is shown below, eqn (3).

Where:

$$
\mathrm{P}=1 / 2 \mathrm{C}_{\mathrm{p}} \rho \mathrm{A}^{2} \mathrm{v}^{3}
$$

$\mathrm{P}=$ power, $\mathrm{C}_{\mathrm{p}}=$ power coefficient, $\rho=$ air density, $\mathrm{A}^{2}=$ cross section of rotor area, $\mathrm{v}^{3}=$ wind speed

Although eqn (3) indicates that, for a given rotor size the power from a turbine varies with the cube of the wind velocity, this equation will provide unrealistic or elevated energy predictions as no account is taken of the effect that a turbine will have on the wind flow.

A more representative calculation relating the power produced from VAWT placed in a modified wind flow through a duct is shown in eqn (4).

Where:

$$
\mathrm{P}=\left(1 / 2 \mathrm{C}_{\mathrm{p}} \rho \mathrm{v}_{-}^{2} \text { freestream }\right)^{*}\left(\mathrm{~A}^{2} \mathrm{v}_{-} \text {duct }\right)
$$

$\mathrm{v}_{\text {_freestream }}{ }^{*}=$ the free stream wind speed and $\mathrm{v}_{\text {duct }}$ represents the wind speed within the duct.

The wind speed distribution shown in Figure 7 was used along with the power distribution curve for the Cleanfield V3.5 turbine to estimate the expected power production for both the internal and external wind regimes, Figure 8 . If the resultant annual energy production in Figure 8 is based on the internal wind regimethen using eqn (3), a17.12\% increase in energy is calculated. . If the calculation is repeated using eqn (4), then an estimated annual energy increase of only $5.71 \%$ is predicted.

Although the field tests did not produce the increase in wind speed as experienced through simulation, the results do however indicate the potential of wind regime modification for VAWT. An increase in energy production of even 5.71\% may sufficiently reduce the payback period of small to medium scale devices, making the financial investment for urban wind integration more attractive

\section{CONCLUSION}

This work has identified through simulation, the optimal shape required to enhance the wind regime for application with a vertical axis wind turbine. The expected performance has been produced using Virtual Wind simulation software. Initial simulation results indicated a significant expected wind increase when comparing simulation results with theoretical projections. Physical testing, using a one third scale model however did not produce such results. The results of the physical field test demonstratedonly a modest increase in average wind speed at approximately $4.59 \%$, significantly less than both the theoretical and simulated results, howevera shifted wind distribution was exhibited, resulting in a greater percentage of higher wind speeds. The cube relationship between wind speed and energy production has resulted in an average projected increased energy output of $5.71 \%$ based on the performance curve of the Cleanfield V3.5 vertical axis wind turbine when the induction effect of the VAWT is taken in to account as reflected in eqn (4). This research has produced unexpected results in that although the average wind speed did not increase significantly, the wind speed distribution was modified sufficiently 
to provide a projected increase in energy production, indicating that wind flow modification has the potential to improve the performance of building mounted vertical axis turbines. The next step is to investigate the potential improvement in energy production that can be realized using full scale structures and a V3.5 wind turbine, provided by Cleanfield Energy.

\section{ACKNOWLEDGMENTS}

The authors would like to thank NSERC for providing funding through the ENGAGE program, which made this collaborative project possible and to Cleanfield Energy, Steve Gruber, Mihail Stern and Tony Verrelli for their participation in the project and through the provision of essential technical information. Thanks also to Professor Greg Bishop in the Engineering Department, NSAC for his assistance with visual basic programming and the development of excel macros used in the analysis of the wind data.

\section{REFERENCES}

[1]. Joselin, G.M., Herbert, S. Iniyan, E. Sreevalsan and S. Rajapandian. A review of wind energy technologies, Renewable and Sustainable Energy Reviews, 11 (2007) 1117-1145

[2]. Ezio, S. and Claudio, C. Exploitation of wind as an energy source to meet the world's electricity demand, WindEngineering 1998;74-76:375-87.

[3]. Thor, S.E. and Weis-Taylor, P. Long Term Research and Development Needs for Wind Energy for the Time Frame 2000-2020, Wind Energy, 2002; 5:73-75.

[4]. IEA $35^{\text {th }}$ Meeting of Experts, "long Term R\&D Needs in Wind Energy for the Time Frame 2000-2020, Proceedings, Aeronautics FFA: Stockholm, 2001

[5]. Busgen, U. andDurrschmidt, W., 2009. The expansion of electricity generation from renewable energies in Germany: A Review based on the Renewable Energy Sources Act Progress Report 2007 and the new German feed-in legislation. Energy Policy, 2009, 37, 2536-2545.

[6]. Butler, L. and Neuhoff, K., 2008. Comparison of feed in tariff, Quota and Auction mechanisms to support wind power development. Renewable Energy, 2008, 33, 1854-1867.

[7]. Couture, T. and Gagnon, Y., An analysis of feed-in tariff remuneration models: Implications for renewable energy investment. Energy Policy, 2011, 38, 955-965.

[8]. 8.Alé, J.A., Petry, M. R., Garcia, S. B.,Simioni, G.C.and G. Konzen

[9]. Performance Evaluation of the Next Generation of Small Vertical Axis Wind

[10]. Turbine.European Wind Energy Conference \& Exhibition, May 7-10, (2007) MIC -

[11]. Milano Convention Centre, Milan, Italy.

[12]. Riegler, H. HAWT versus VAWT Small VAWTs find a clear niche.

[13]. Elsevier Science Ltd., No. 1471 0846, Refocus July/August 2003, pp 44-46.

[14]. 10.Mazharul I, Ting,D. and Fartaj, A. Aerodynamic models for Darrieus-type straight-bladed vertical axis wind turbines" Renewable and sustainable energy reviewsVol 12, Issue 4 May 2008 pp 1087-1109.

[15]. 11. Heath, M. A., WalsheJ. D. and Watson,S. J. Estimating the Potential Yield

[16]. of Small Building-mounted Wind Turbines, Wind Energy. 2007; 10:271-287

[17]. 12. Bertenyi, T., Wickins, C.andMcIntosh,S. Enhanced Energy Capture Through Gust Tracking in the Urban Wind Environment, $48^{\text {th }}$ AIAA Aerospace Sciences Meeting, January 4-7, 2010, Orlando, FL.

[18]. 13. Beller, C. Urban wind Energy-State of the Art 2009, RISO Report, National Laboratory for Sustainable Energy, Technical University of Denmark.

[19]. 14. Beller, C. Layout Design for a Venturi to Encase a Wind Turbine Integrated in a High Rise, RISO Report (2008), National Laboratory for Sustainable Energy, Technical University of Denmark.

[20]. 15. Robert K. W. Dannecker and Andrew D. Grant, Investigations of a Building-Integrated Ducted Wind Turbine Module,Wind Energy. 2002; 5:53-71

[21]. 16. Grant, A. and Kelly, N. The development of a Ducted Wind Turbine Simulation Model, $\underline{8}^{\text {th }}$ International IBPSA Conference, Eindhoven, Netherlands, Aug 11-14 2003.

[22]. 17.Renewable Devices Swift Turbines Ltd (2007), SWIFT Rooftop Wind Energy SystemTM, information sheet published by Renwable Devices SWIFT Turbines Ltd.

[23]. 18.Windsave, http://www.windsave.co.uk, last accessed 25th May 2007.

[24]. 19.Urban Wind Energy, http://www.urbanwindenergy.org.uk/index.asp?PageID=84, last accessed 25 th May 2007.

[25]. 20.Mertens S (2006), Wind energy in the built environment', ISBN: 0906522358, Multi-Science, Brentwood, Essex, UK.

[26]. 21. BWEA Small Wind Turbine Performance and Safety Standard (March 2007)http://www.bwea.com/pdf/small/BWEA\%20SWT\%20Performance\%20and\%20Safety\%20Standard\%20Clar ification\%20Note\%20V1\%200.pdf

Table 1 Recorded results for interior multiplier factor for exterior wind speeds and cube ratio.

\begin{tabular}{|c|c|c|c|c|c|c|}
\hline & \multicolumn{6}{|c|}{ Exterior Wind Speed (m/s) } \\
\hline Ratio & 2 & 4 & 6 & 8 & 10 & 12 \\
\hline 2.21 & 0.959565 & 0.959575 & 1.090305 & 1.090236 & 1.0877 & 1.0903 \\
\hline 5.39 & 1.30923 & 1.230905 & 1.34093 & 1.334838 & 1.33468 & 1.342575 \\
7.25 & 1.37908 & 1.280875 & 1.414797 & 1.4127 & 1.41357 & 1.4118 \\
7.91 & 1.60531 & 1.440598 & 1.557312 & 1.554013 & 1.55658 & 1.550367 \\
\hline
\end{tabular}




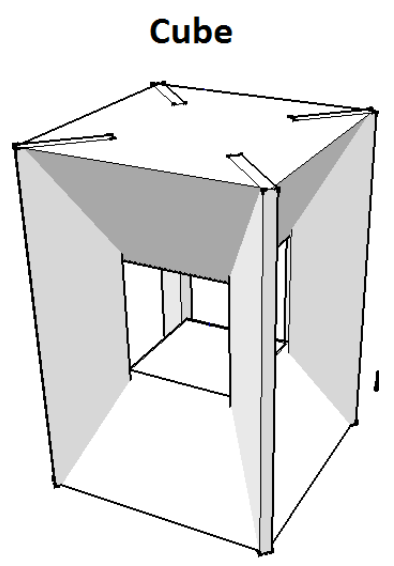

Figure 1(a) Cube Design

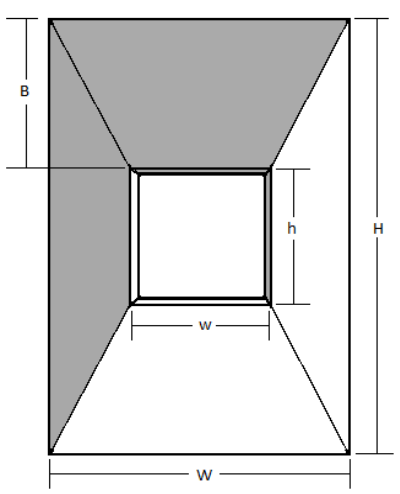

Figure 1(b). Cube Dimensions

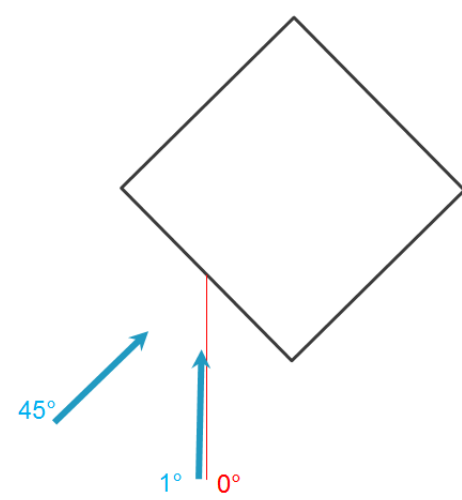

Figure 2. Angle of prevailing Wind Direction

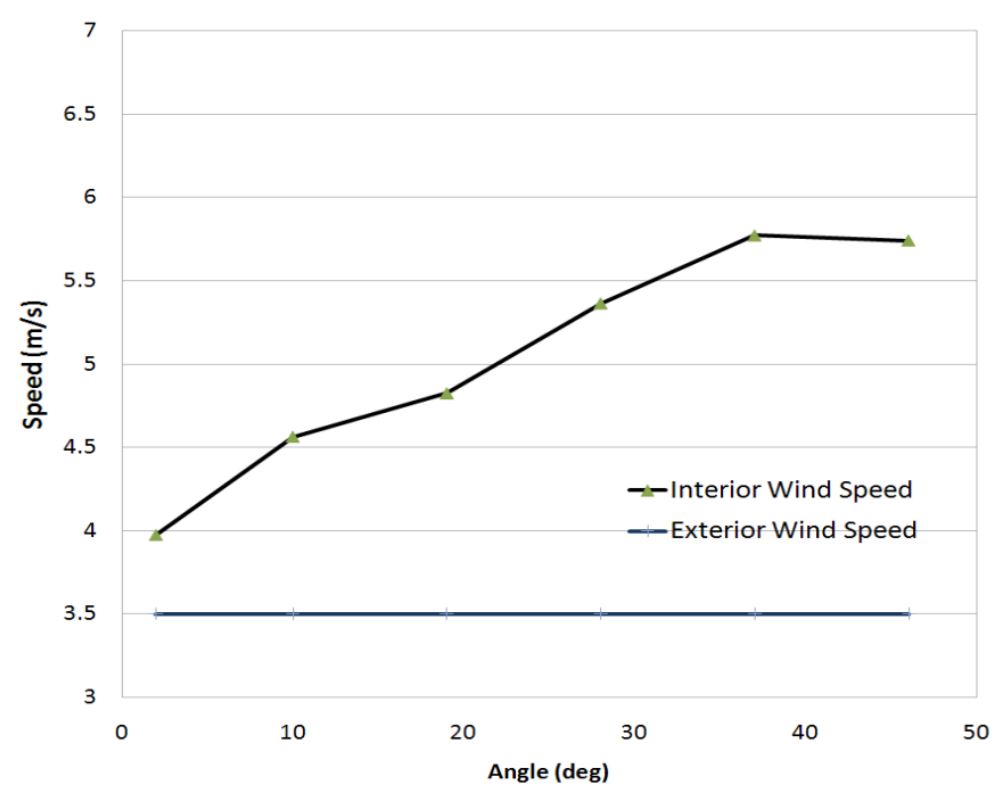

Figure 3.Comparison of prevailing wind direction for a fixed wind Speed of $3.5 \mathrm{~m} / \mathrm{s}$.

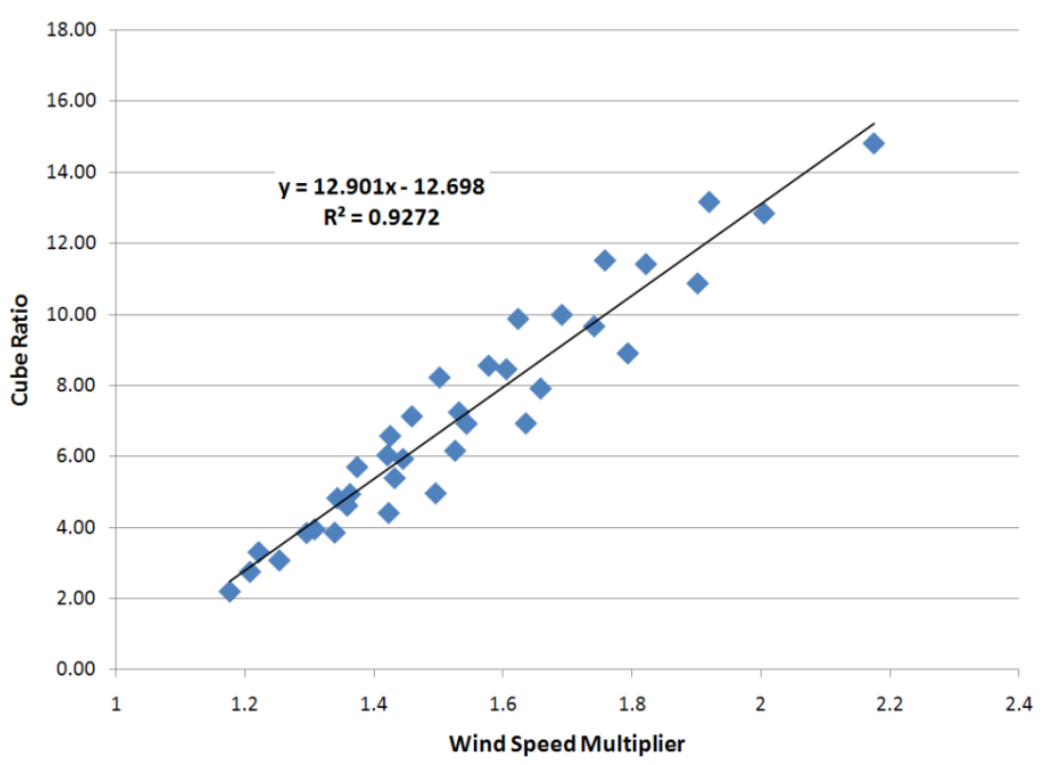

Figure 4. Plot of cube ratio versus wind speed multiplier for 36 different cube configurations at a fixed external wind speed of $3.5 \mathrm{~m} / \mathrm{s}$ at a prevailing wind angle of $36^{\circ}$. 


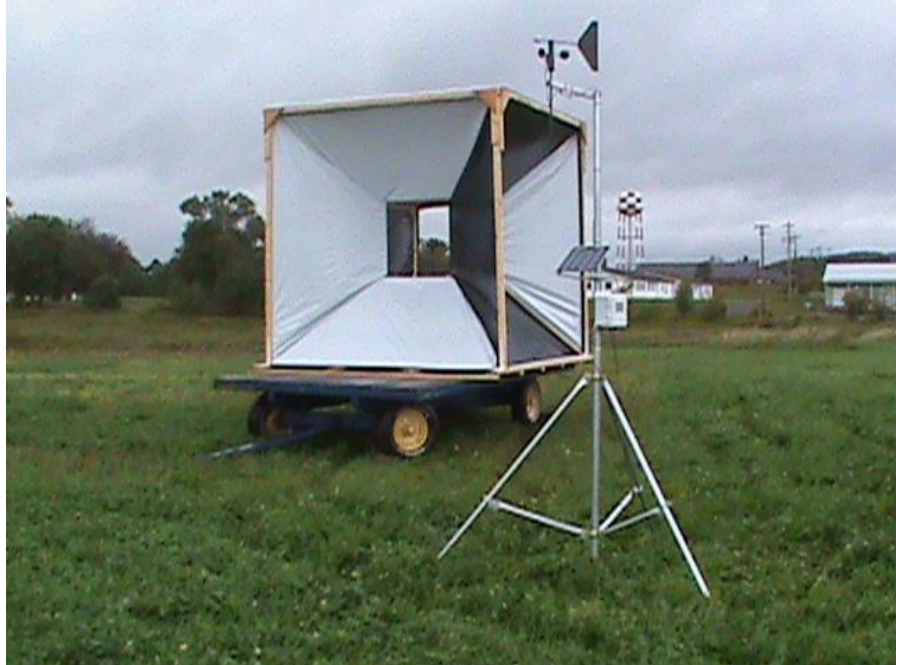

Figure 5.Image of field test with cube and free standing wind speed sensor.

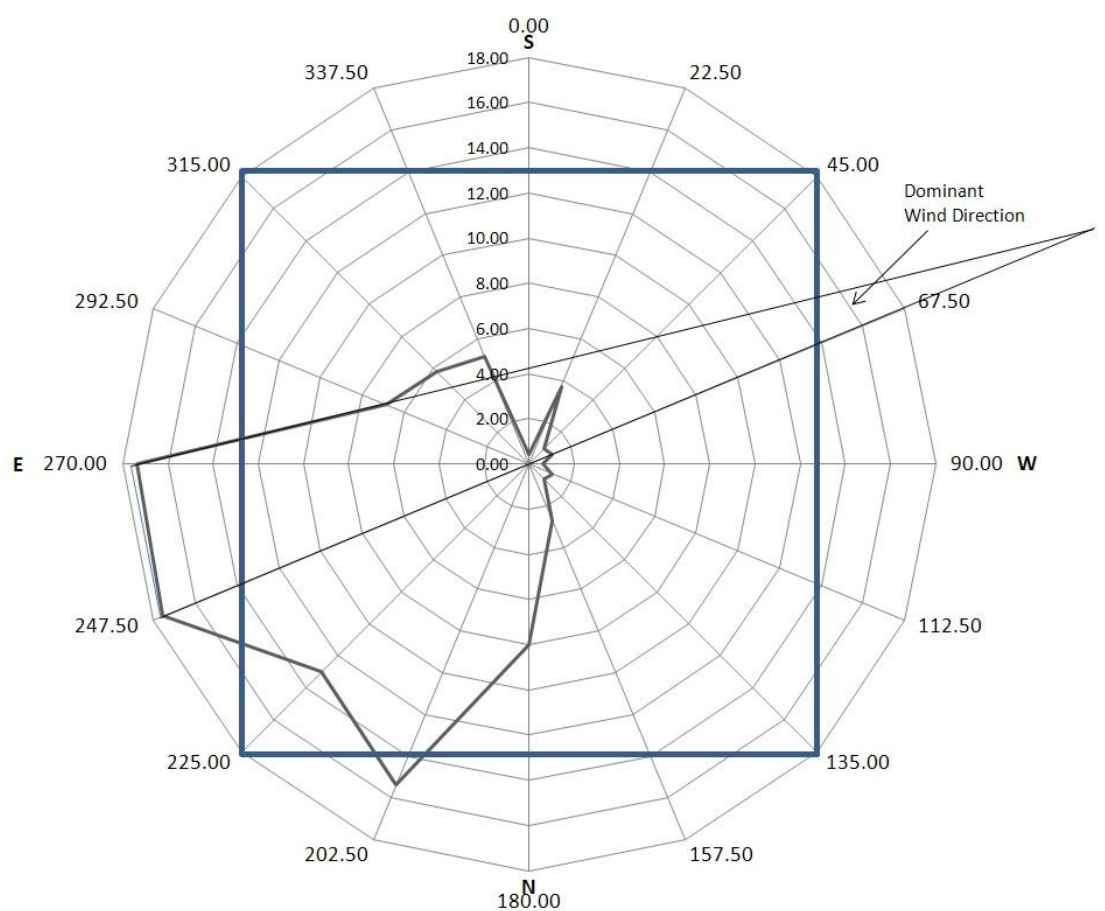

Figure 6. Wind rose and overlay of cube, with prevailing wind direction identified. 


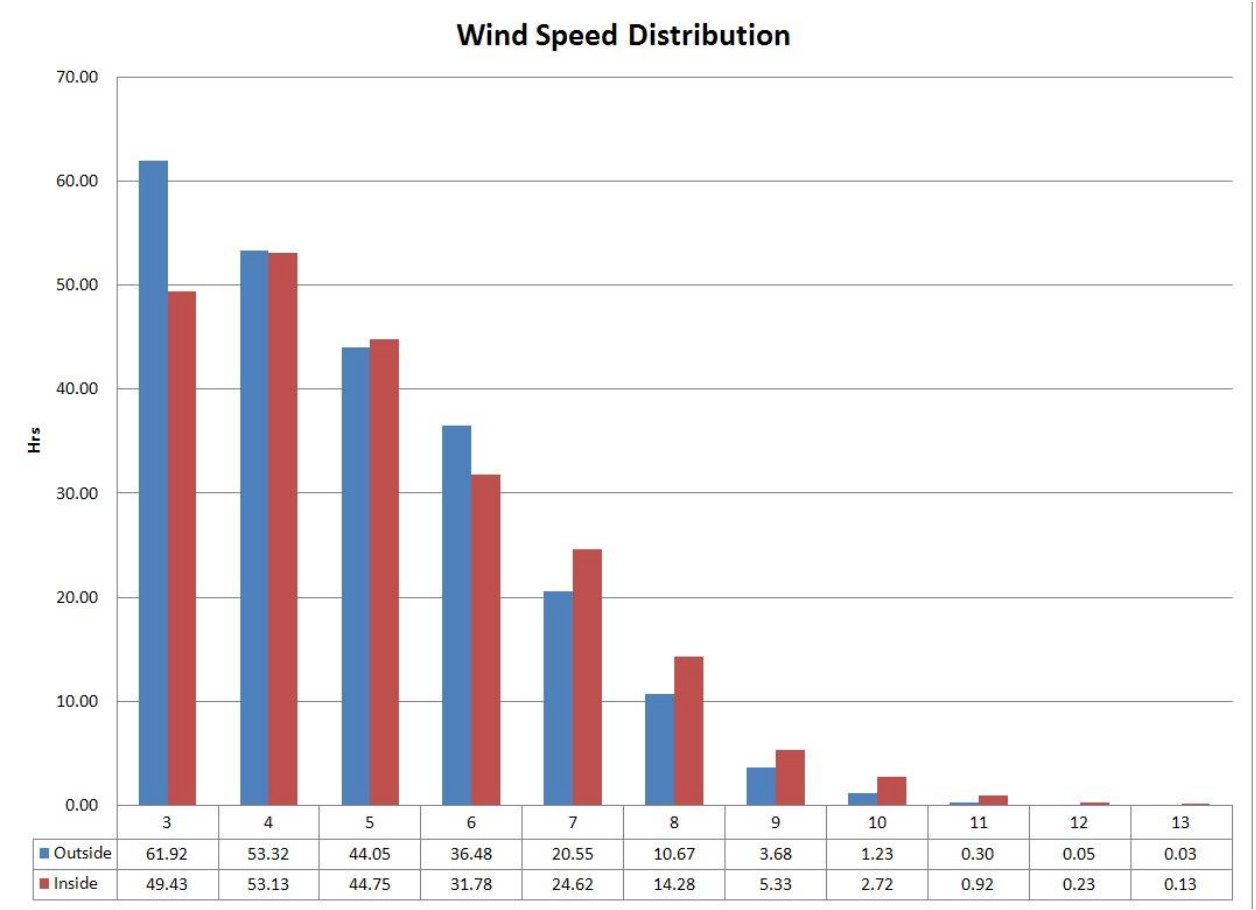

Figure 7. Wind speed distribution recorded inside and outside the cube.

\section{Calculated Energy Distibution}

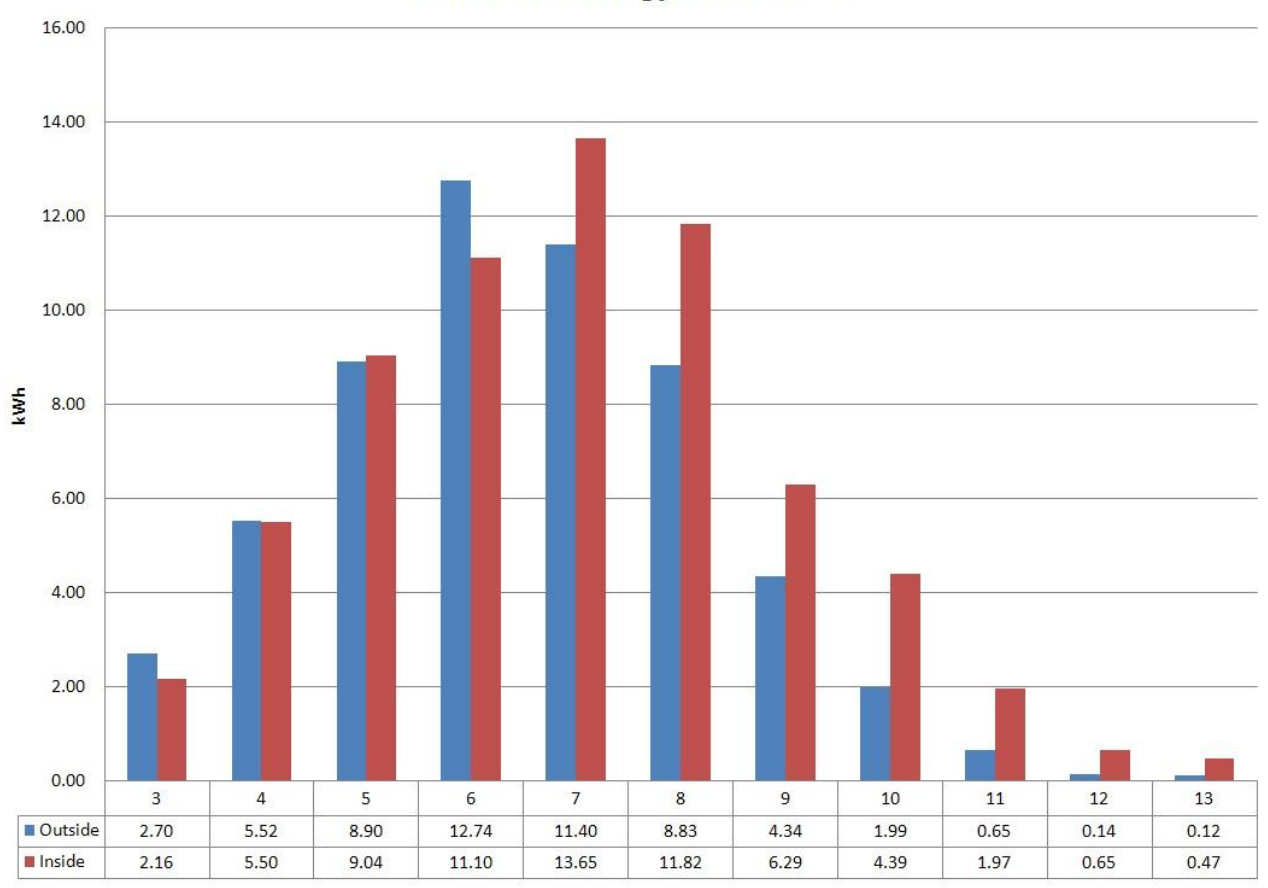

Figure 8. Calculated energy distribution based on the internal and external wind distributions and the manufacturer's power curve. 